\title{
TRANSPORTE POR VANS - O QUE CONSIDERAR NO PROCESSO DE REGULAMENTAÇÃO?
}

\section{Ronaldo Balassiano, PhD.}

Programa de Engenharia de Transportes

PET / COPPE - UFRJ

\section{RESUMO}

A redução nas taxas de importação nos anos 90 contribuiu para o aumento da importação de veículos novos que não são atualmente produzidos pelas montadoras instaladas no Brasil. As vans têm se popularizado em cidades como o Rio de Janeiro no atendimento à demanda de serviços considerados não convencionais ou informais. Existem ainda casos constatados da utilização destas vans em rotas normalmente operadas por serviço regular de ônibus urbano.

Constata-se que as Secretarias (Municipal, Estadual) responsáveis pelo gerenciamento do setor de Transportes no Rio de Janeiro, estão preocupadas com a regulamentação deste serviço que vem se popularizando e se tornando uma alternativa viável ao usuário do transporte regular além de oferecer uma alternativa ao usuário do carro particular. $O$ objetivo deste trabalho é discutir o papel desempenhado por este tipo de serviço em grandes centros urbanos, e também aspectos gerais que deveriam ser considerados neste processo de regulamentação. Discute-se também o problema atual dos transportes coletivos na cidade do Rio de Janeiro e conclui-se que as vans têm potencial, se regulamentadas de forma adequada, para contribuir na melhoria do transporte público da cidade.

\section{ABSTRACT}

Import tax reductions in the 90's have contributed to an increase in vehicles importation, currently not assembled in Brazil. Vans are very popular in cities such as Rio de Janeiro, responding to the demand of non-conventional or informal transport services. The are also some cases where these vans are replacing bus services on conventional bus routes. 
The Municipal and State Transport Secretaries are concerned with how to regulate these services. The vans are turning into a viable alternative to public transport users and to car users too. The main objective of this paper is to discuss the role played by this type of service in busy urban centres and also some aspects to be taken into account in the regulation process. The current public transport problem in Rio de Janeiro is also focused and the conclusion is that the vans have the potential to improve public transport use in the city, if adequately regulated.

\section{INTRODUÇÃO}

A redução nas taxas de importação nos anos 90 contribuiu para o aumento da importação de veículos novos que não são atualmente produzidos pelas montadoras instaladas no Brasil. A diversidade de marcas e modelos hoje à disposição do consumidor é grande e abrange desde carros de luxo até veículos do tipo "van" com capacidade para transportar em média 10-15 passageiros. Estas vans tem se popularizado em cidades como o Rio de Janeiro no atendimento à demanda de serviços considerados não convencionais ou informais. É usual encontrar-se nos classificados dos principais jornais, anúncios com oferta para a prestação de serviços de transporte de passageiros em seus deslocamentos para shows, restaurantes, compras em shoppings e também para o transporte de alunos de diversas escolas, entre outros. Trabalhadores de várias empresas, grupos de amigos, vizinhos e outros têm também utilizado estes serviços nos seus deslocamentos diários casa-trabalho-casa. Existem ainda casos constatados da utilização destas vans em rotas normalmente operadas por serviço regular de ônibus urbano. Este serviço se apresenta como uma alternativa viável de transporte para grupos diversos de usuários além de ampliar as alternativas de mercado de trabalho para operadores independentes.

A Secretaria Municipal de Transportes do Rio de Janeiro criou uma regulamentação para este serviço de vans (Decreto 14918 de 26/6/96), visando garantir ao sistema de transporte público já regulamentado na cidade, sua condição soberana no transporte de passageiros. O decreto estabelece que as vans só podem ser usadas para transportar turistas, pessoas organizadas para assistir espetáculos, funcionários de empresas e portadores de deficiência física. Determina ainda que somente empresas e autônomos cooperados (associados em cooperativa) podem transportar esses passageiros. Existem atualmente 14 empresas licenciadas na SMTU (Superintendência Municipal de Transportes Urbanos), e um total de 539 veículos (quase $10 \%$ da frota de ônibus urbano da cidade), o que podeconsiderado um indicador de sucesso de operação. 
Paralelamente a esta ação, a Secretaria de Estado de Transportes manifestou sua preocupação com a concorrência predatória destes serviços de vans e também avalia a melhor forma de regulamentação destes serviços. Observa-se assim, que as duas Secretarias responsáveis pelo gerenciamento do setor de transportes no Rio de Janeiro, estão atentas ao processo de regulamentação de um serviço que vem se popularizando e se tornando uma alternativa viável ao usuário do transporte regular além de oferecer uma nova alternativa ao usuário do carro particular. Desta forma, julga-se oportuno, discutir o papel desempenhado por este tipo de serviço em grandes centros urbanos e também aspectos gerais a serem considerados neste processo de regulamentação.

A partir da atual proposta de regulamentação, alguns aspectos relativos às condições atuais do transporte rodoviário urbano na cidade do Rio de Janeiro devem ser retomados para que esta proposta não venha acarretar uma possível desmotivação do usuário destes serviços, nem tampouco ameaçar através de concorrência predatória os serviços regulares de transporte de passageiros atualmente disponíveis.

Este trabalho pretende discutir alguns aspectos que devem ser levados em consideração no processo de regulamentação das vans, e está estruturado da seguinte forma: a seção 2 apresenta uma discussão do papel desempenhado por veículos de transporte coletivo de baixa capacidade, tendo como referência o caso dos minibuses na Inglaterra. Na seção 3, algumas possíveis razões para o surgimento e o sucesso deste tipo de serviço em uma cidade como o Rio de Janeiro são apresentadas. A seção 4 discute alguns aspectos relacionados com a forma de regulamentação proposta para estes serviços e finalmente na seção 5 são apresentadas as principais conclusões do trabalho.

\section{O PAPEL DESEMPENHADO PELOS MINIBUSES}

As vans utilizadas atualmente na cidade do Rio de Janeiro não são necessariamente iguais aos minibuses hoje utilizados em países como a Inglaterra. Porém, se considerarmos que os minibuses (com capacidade de transportar em torno de 20-25 passageiros) surgiram como um desdobramento natural da utilização de veículos que transportavam cerca de 15 passageiros (capacidade similar à das vans), julga-se relevante analisar alguns aspectos discutidos por acadêmicos e profissionais do setor que estudaram o fenômeno 
da expansão deste tipo de veículo em áreas urbanas. Ressalte-se ainda que fenômeno similar foi identificado em países como o Chile, onde veículos de menor capacidade de transporte de passageiros se incorporaram ao sistema de transportes públicos de cidades como Santiago.

É importante destacar entretanto, que veículos de baixa capacidade classificados por diversos autores como paratransit, têm sido utilizados por razões diversas em várias cidades do mundo. Alguns desses exemplos incluem: rickshaws e cycle rickshaws, responsáveis por $15 \%$ do mercado de transporte público na Índia (Umrigar et al, 1991); tuk-tuks (um tipo de ciclomotor de três rodas) e silor leks (um pequeno veículo de 4 rodas) desempenham um papel importante na provisão de transporte rápido para pessoas e mercadorias em Bangkok - Tailândia (Tanaboriboon e Agad, 1990; Tanaboriboon e Madrona, 1990). Outros exemplos de veículos de baixa capacidade para transporte de passageiros em áreas urbanas de diferentes cidades do mundo podem ser encontrados em Dourado (1995). No caso do Brasil, alguns estudos já foram realizados analisando o papel desempenhado no transporte de passageiros por veículos do tipo kombi, em cidades como Brasília e Recife. Veículos de baixa capacidade são também bastante populares no transporte de escolares em diversas cidades.

O aparecimento de ônibus de baixa capacidade - minibus - na Inglaterra aconteceu antes mesmo da adoção da desregulamentação da operação de sistemas de ônibus urbano naquele país. Foi porém após a desregulamentação (1985) que este serviço se expandiu de forma considerável. Para um país que estava acostumado a utilizar ônibus de dois andares (double-deck) em praticamente todas as rotas urbanas, o aparecimento e o sucesso dos minibuses foi motivo de muitos estudos e análises tanto no nível acadêmico quanto no nível empresarial.

De acordo com White e Cassidy (1993), já haviam cerca de 9.000 minibuses ao final da década de 80 na Inglaterra. Os autores consideram que nos casos em que mais ônibus-km precisam ser operados quando se substitui o ônibus convencional pelo minibus, a viabilidade financeira destes serviços recairá na capacidade de se atrair mais passageiros. Eles estimam que os custos de operação por $\mathrm{km}$ de um minibus seja cerca de $70 \%$ do custo do ônibus convencional. Sendo assim, nesta substituição, se for preciso dobrar a freqüência do serviço (dada sua menor capacidade de transporte), os custos totais de operação (comparados com o ônibus convencional) deverão crescer em cerca de $40 \%$. Para se alcançar um equilíbrio operacional a de- 
manda deverá crescer na mesma proporção, a fim de garantir a cobertura dos custos adicionais. Eles consideram ainda que em linhas troncais onde o ônibus convencional oferece um serviço freqüente e confiável, a conversão para uma operação com minibuṣes não seria vantajosa. Uma outra estratégia considerada para justificar a utilização destes minibuses seria a penetração em áreas residenciais de acesso mais difícil ao ônibus convencional. Consideram ainda que para se obter um crescimento de demanda que justifique a conversão seria importante que os usuários estivessem bem informados sobre os serviços oferecidos.

Banister (1992) considera que os minibuses ocupam um espaço intermediário no mercado de transporte rodoviário urbano, entre o táxi e o ônibus convencional. Estes veículos aumentam a sensação de um serviço personalizado e ao mesmo tempo contribuem para o aumento da percepção de segurança do passageiro. No caso dos motoristas destes veículos, Banister (1992) considera que existem também algumas vantagens sobre o ônibus convencional: existe uma maior mobilidade e flexibilidade de direção, além de propiciar um contato mais direto com o passageiro.

Como exemplo de sucesso da operação de minibuses, White (1991) reporta o caso de Exeter - Inglaterra onde no período entre 1984 e 1990 o número total de passageiros transportados por ônibus aumentou de 14.000 para 40.000 por dia, em um aumento de quase $200 \%$. Ressalte-se que em geral o número de passageiros utilizando o transporte coletivo por ônibus naquele país vem historicamente caindo ao longo das últimas décadas (Balassiano, 1995). Existem ainda os casos de Swansea e Newbury, onde a entrada em serviço dos minibuses não só aumentou o número de passageiros diários no sistema como identificou-se que $50 \%$ destas viagens adicionais eram geradas por antigos usuários de carro particular. Uma possível justificativa no caso de Swansea são os intermináveis congestionamentos verificados na parte central da cidade. Os usuários de carro particular se sentiram atraídos por um serviço de qualidade e alta freqüência que além de reduzir o stress de dirigir nesta área central evita o transtorno da perda de tempo na busca de uma vaga para estacionar (White e Cassidy, 1993).

De acordo com Glaister (1985) existem vantagens mas também algumas desvantagens na utilização dos minibuses. Ele destaca como principais vantagens: os veículos, por terem que embarcar e desembarcar passageiros menos freqüentemente, alcançam velocidade comercial superior ao ônibus convencional diminuindo com isso o tempo total de viagem dos usuários; 
vários veículos pequenos teriam maior mobilidade, em termos de alteração de rotas ou mesmo na criação de novas rotas, quando comparados com poucos ônibus convencionais; estes novos serviços ou variações de serviços existentes poderiam produzir um aumento no número de usuários principalmente daqueles que não se utilizam de ônibus ou preferiam viajar à pé dada a freqüência do ônibus convencional; o aumento do número de passageiros poderá gerar maior receita para os operadores com perspectivas de maiores investimentos em novos serviços. Ainda de acordo com o mesmo autor, alguns efeitos adversos da introdução deste tipo de serviço são apontados: aumento no número total de veículos em circulação gerando mais congestionamento de tráfego; o veículo convencional permite uma distribuição de custos mais eqüitativa entre usuários. Se o aumento da frota de minibuses for tal que implique em redução da frota de ônibus convencional de forma substancial, é possível que a camada da população de menor renda seja penalizada com tarifas maiores nos minibuses.

Glaister (1986) considera também que a introdução de minibuses em corredores já operando com alta densidade de ônibus convencionais poderia gerar competição através do oferecimento de um serviço mais ágil a um preço maior. A contrapartida, como já observado anteriormente, seria o possível aumento de congestionamento de tráfego nestas vias.

É importante nesta análise da utilização dos minibuses em centros urbanos avaliar a percepção do público à expansão deste serviço. No caso da Inglaterra, Banister e Mackett (1990) enumeram várias pesquisas com usuários realizadas em diferentes cidades. Em uma pesquisa em Sunderland, do total de usuários entrevistados, cerca de $87 \%$ apontava como vantajoso o aumento da facilidade de uso deste sistema devido à maior frequiência; cerca de $84 \%$ considerou o conforto deste tipo de veículo variando entre bom e médio; a gentileza do motorista foi considerada entre boa e muito boa por cerca de $69 \%$ dos entrevistados e a pontualidade e confiança no serviço foi considerada entre boa e muito boa por $62 \%$ dos entrevistados. Um aspecto negativo identificado foi o espaço destinado a bagagem, considerado entre inadequado e muito ruim por mais de $83 \%$ dos que responderam à pesquisa. Em outra pesquisa realizada na cidade de Swansea observou-se que $57 \%$ dos entrevistados viajando nos minibuses julgou o ambiente mais seguro que o do ônibus convencional. Por outro lado $55 \%$ dos entrevistados considerou que os minibuses trafegam em geral mais lotados que os ônibus convencionais. 
O fato destes ônibus trafegarem normalmente lotados pode ser um indicador do grau de popularidade dos mesmos junto aos usuários (Banister e Macket, 1990). Estes autores consideram que o uso dos minibuses como alimentadores de serviços troncais, deverá ser mais eficiente que usá-los em ligações com demanda elevada. Em condições e vias congestionadas, minibuses não deverão oferecer vantagem significativa em termos de tempo de viagem, se comparados aos ônibus convencionais. Eles ainda consideram que em rotas radiais de relativamente baixa densidade residencial, estes minibuses poderiam ser usados como serviços expressos a tarifas especiais e promovidos de forma diferenciada do serviço convencional.

De acordo com White et al (1992), no caso da conversão de serviços de ônibus regulares por minibuses, em rotas onde a freqüência é baixa e a taxa de ocupação dos veículos também, benefícios substanciais poderão ser gerados. Estes benefícios viriam de um excedente para o operador e também de benefícios para usuários através da redução do tempo total de viagem (tempo de espera, tempo de viagem no veículo, e tempo andando até o ponto de parada). Em um estudo de caso para a cidade de Londres, os autores observaram que o tempo de espera pelo ônibus não se reduz necessariamente nesta conversão, porém um aumento na demanda pelos serviços é um possível indicador da existência de benefícios ao usuário.

Em que pese a diferença entre os minibuses e as vans em termos de capacidade total de transporte, algumas semelhanças operacionais são evidentes. Já a motivação para operar este tipo de serviço parece não ser a mesma. No caso da Inglaterra, este serviço de transporte operando veículos de menor capacidade que o onibus convencional se intensificou após a desregulamentação, e basicamente como uma alternativa aos operadores já estabelecidos, de redução de custos operacionais crescentes em algumas rotas. No caso do Rio de Janeiro, o sucesso deste serviço pode ser associado principalmente à baixa qualidade dos atuais serviços de transporte público na cidade. Este aspecto será considerado mais detalhadamente na próxima seção, onde se discutem alguns fatores responsáveis pelo sucesso no Rio de Janeiro da operação das vans. 


\section{ALGUMAS RAZÕES PARA O SUCESSO DAS VANS NO RIO DE JANEIRO}

Antes de discutir aspectos relacionados à regulamentação deste tipo de serviço, é interessante e mesmo fundamental entender-se a razão do sucesso da operação destes veículos. Alguns dados relativos aos sistemas de transportes da cidade do Rio de Janeiro podem servir como um indicador do atual nível de serviço oferecido pelos sistemas de transportes públicos regulamentados.

O rápido aumento da população urbana gerou um aumento no número de viagens na cidade, e mais especificamente em viagens para trabalho. É também possível observar-se uma grande concentração de carros particulares nas ruas, sobretudo nos horários de rush. O sistema de ônibus urbano é o principal meio de transporte coletivo, com uma demanda média estimada superior a 5,0 milhões de passageiros por dia. De acordo com os operadores privados (FETRANSPOR) o número total de passageiros transportados diariamente por este modal em setembro de 1996 era de 7,0 milhões de passageiros-dia. Este número divulgado para 1996 já havia sido estimado em levantamento realizado na cidade no final de 1993 (Balassiano, 1995). Observações mais recentes da operação das diversas linhas de ônibus na cidade do Rio de Janeiro sugerem que este número pode estar próximo a 9,0 milhões de passageiros-dia. Este volume estimado baseia-se em: cada ônibus opera normalmente em um regime de 8 viagens por dia ao longo de todo dia (viagem completa - ida-e-volta); existe alta rotatividade de passageiros nas principais linhas de ônibus operando na cidade com possibilidade de se atingir uma média de 100 passageiros transportados por sentido por viagem (200 passageiros em cada viagem completa); existem cerca de 6000 ônibus operando na cidade. Com base nesses números, é possível que o sistema transporte um total de 9,6 milhões de passageiros-dia. Quando se considera toda a região metropolitana o número de passageiros diários no sistema poderá estar na faixa de 12-15 milhões. É importante destacar que este número é uma estimativa que leva em consideração a alta rotatividade de passageiros na maioria das rotas operadas, o que não significa necessariamente que estes ônibus estejam trafegando lotados durante todo o tempo e nos dois sentidos de tráfego. Este fato (alta rotatividade), já havia sido identificado anteriormente (Balassiano, 1995).

Sistemas de transporte público como o Metrô, trens e barcas são responsáveis por apenas um pequeno percentual de passageiros transportados dia- 
riamente. A tabela 1 apresenta o percentual de passageiros transportados por cada uma destas modalidades de transporte público de acordo com dados oficiais divulgados pelo poder concedente.

Tab. 1 - Passageiros transportados - região metropolitana - Rio de Janeiro

\begin{tabular}{|l|r|r|r|r|}
\hline MODO & \multicolumn{1}{l}{$\begin{array}{l}\text { PASSAG. TRANSP. } \\
\text { (MILHÃO - 1985) }\end{array}$} & \multicolumn{3}{c|}{$\begin{array}{l}\text { PASSAG. TRANSP. } \\
\text { (MILHÃO - 1995) }\end{array}$} \\
\hline Trens & 274 & 9.4 & $\mathbf{1 3 6}$ & 5.2 \\
\hline Metrô & 98 & 3.3 & 100 & 3.8 \\
\hline Barcas (aero-barcas) & 52 & 1.8 & 24 & 1.0 \\
\hline Ônibus & 2500 & 85.5 & 2380 & 90.0 \\
\hline Total & $\mathbf{2 9 2 4}$ & $\mathbf{1 0 0 . 0}$ & $\mathbf{2 6 4 0}$ & $\mathbf{1 0 0 . 0}$ \\
\hline
\end{tabular}

FONTE: SMTU, METRÔ, CONERJ, CBTU em Guedes et al (1996).

Os números apresentados na tabela 1 apontam para a degradação dos serviços de transporte público na cidade. O número total de passageiros transportados em 1995 (segundo fontes oficiais) foi menor que em 1985, a despeito do crescimento da população na cidade. Algumas hipóteses podem ser consideradas para explicar este fenômeno: queda no nível de atividade econômica; aumento do número de viagens por meios alternativos (táxis, motocicletas, bicicletas, viagens à pé); transferência de usuários para utilização do carro particular (sempre que isto é viável); ou ainda, falha na coleta de informações sobre demanda nos diferentes sistemas.

Embora seja possível identificar-se alguma queda de atividade econômica em parte deste período de 10 anos, esta queda não deveria ser suficiente para explicar sozinha esta redução no numero de passageiros transportados pelos diversos modais. A substituição do uso do transporte público por meios de transporte alternativos deverá estar também contribuindo para este resultado final, não sendo possível aqui estimar-se (por falta de dados) o percentual de contribuição de cada aspecto isoladamente. Entretanto, parece evidente, que o aumento da frota particular e sua utilização na cidade também contribui diretamente para explicar uma possível queda no número total de passageiros transportados pelo transporte público regular na cidade. 
Dados da frota da região metropolitana mostram que esta cresceu em média a uma taxa de $4 \%$ ao ano nos últimos 10 anos. A frota que era de 1,1 milhão de veículos em 1986 (GEIPOT, 1987), sendo cerca de 85\% da frota formada por carros particulares, passou para 1,7 milhão em 1996, de acordo com dados do DETRAN (Departamento de Trânsito do Rio de Janeiro). Assumindo-se uma taxa de ocupação média de 1,5 passageiros por veículo particular, e cada veículo fazendo pelo menos uma viagem pendular por dia (casa-trabalho-casa) num total de 260 dias úteis por ano, pode-se assumir que parte considerável destes usuários perdidos para o transporte público (de acordo com a tabela 1) estão utilizando o carro particular nos seus deslocamentos diários. Com base nestes dados, a estimativa é de que cerca de $70 \%$ dos 284 milhões de usuários perdidos pelo sistema de transporte público (quando se comparam os passageiros transportados em 1985 e 1995 - tabela 1), estejam utilizando carros particulares em suas viagens diárias ( 255 mil veíc. $\times 1,5$ pass. por veíc. $\times 2$ viagens por dia $\times 260$ dias por ano $=$ 199 milhões). Esta estimativa assume que pelo menos $50 \%$ da frota adicional no período (total de 300 mil veículos, sendo $85 \%$ deste total formado por carros particulares - 255 mil) esteja em circulação nos dias úteis.

Este fenômeno contribui para a criação de um círculo vicioso. Com a transferência de usuários do sistema de transporte público para o transporte privado, a tendência natural dos operadores é reduzir freqüência (menos usuários para o mesmo serviço). Com isso a qualidade do serviço cai ainda mais e outros passageiros tenderão a se transferir para o uso do carro particular (ou outra opção) sempre que viável. Transportes alternativos não regulamentados (ônibus "piratas" - sem registro, kombis, vans, etc.) tendem a ter também um aumento de demanda devido a queda do nível de serviço dos sistemas convencionais. Segundo Couto e Pereira (1992), entre outros fatores, a existência de serviços alternativos (clandestinos) está vinculada à incapacidade da oferta em atender a demanda existente.

Finalmente, é também possível que o número total de passageiros transportados em 1995 (tabela 1) esteja subestimado. Como referido anteriormente, o número de passageiros transportados por ônibus pode ser superior ao apresentado.

Um outro aspecto possivelmente contribuindo para a queda da qualidade dos serviços regulares de transporte na cidade está vinculado a desorganização administrativa dos diversos órgãos responsáveis pela gestão dos 
diferentes sistemas e vias. Enquanto os trens de subúrbio e o Metrô são administrados pelo governo estadual, os ônibus são controlados pelo governo municipal. A única linha de bondes que ainda opera na cidade pertence a uma empresa do estado (esta empresa passa por processo de extinção), mas opera em vias municipais e é regulamentada pelo município. Existem ainda ônibus intermunicipais que trafegam na cidade, mas têm a operação controlada pelo governo do estado. As vias e o trânsito são mantidas e operadas pelo município, porém a atribuição de multar os infratores é da polícia militar, que é subordinada ao governo do estado. Esta diversidade de órgãos e atribuições contribui para a má qualidade dos serviços convencionais uma vez que existe pouca integração física e tarifária entre os diferentes modais (muitas vezes não existe integração alguma). Não há também qualquer coordenação operacional entre os diversos sistemas. Não existe adequação dos terminais, de forma a facilitar a transferência dos usuários entre diferentes modalidades de transporte. A falta de coordenação entre estes órgãos responsáveis pela gerência dos diferentes sistemas e do trânsito se reflete no atual nível de serviço oferecido ao usuário. Destaque-se ainda que os problemas de coordenação e gestão dos diversos sistemas de transportes não chegam a ser um "privilégio" da cidade do Rio de Janeiro e já foram abordados anteriormente por outros autores (Couto e Pereira, 1992; Dourado, 1995).

O melhor exemplo dos reflexos desta desorganização administrativa é a operação do próprio serviço de vans. Enquanto o município se apressa em apresentar regulamentação provisória para este serviço, estabelecendo exclusividade para o transporte de turistas e escolares, o estado se posiciona no sentido de coibir a utilização das vans para o transporte de passageiros, uma vez que este tipo de serviço estaria competindo de forma predatória com serviços de transportes regulamentados. E a que esfera administrativa estariam as vans subordinadas? Ao estado ou ao município? Esta indefinição de atribuições, mostra a dificuldade atual de lidar com os problemas de transportes na cidade e está refletida na operação do trânsito e na desorganização dos sistemas de transportes públicos.

Considerando-se não ser o objetivo deste trabalho discutir em que esfera de poder (municipal ou estadual) devem ser regulamentadas as vans, julga-se importante analisar alguns aspectos que deveriam ser levados em conta no processo de regulamentação do serviço de vans. Espera-se que essa análise possa contribuir no sentido da melhoria da operação do transporte público na cidade. A seção 4 se dedica a discutir alguns desses aspectos. 


\section{A REGULAMENTAÇÃO DO SERVIÇO DE VANS}

\subsection{Potencial de Utilização em Áreas Urbanas}

O primeiro aspecto a ser considerado no processo de regulamentação das vans está relacionado à adequação da operação destes veículos em centros urbanos. As vans devem ser regulamentadas de forma a contribuir para a melhoria do desempenho do serviço de transporte coletivo já operando na cidade. Elas devem se integrar ao sistema de transporte regular de forma a aumentar a capacidade total do sistema, além de oferecer uma nova alternativa de transporte aos usuários. Esta forma de abordagem do problema, parece estar de acordo com o que propõe Dourado (1995) quando sugere que a questão colocada na forma de oposição entre transporte formal e informal não é adequada. O importante seria considerar a oferta como um todo, admitindo a coexistência de diversas formas de transportes, evoluindo de forma dinâmica.

Como observado por Banister (1992) no caso dos minibuses, as vans ocupam um lugar intermediário entre o ônibus e o táxi. Elas oferecem uma privacidade menor que a oferecida aos usuários do táxi porém um conforto superior e maior flexibilidade que a oferecida pelo serviço de ônibus regular. Sendo assim, elas não deveriam ter uma regulamentação igual àquela existente para o serviço de ônibus. O mesmo raciocínio é válido para táxis.

Com base nestes aspectos, destacam-se à seguir algumas possíveis estratégias operacionais com chances de sucesso na operação de veículos do tipo van: a) atração de usuários do carro privado em viagens do tipo casa-trabalho-casa, casa-escola-casa; b) potencial de operação como sistema alimentador de sistemas troncais (corredores de ônibus, trens, metrô); c) potencial de substituição de veículos de maior capacidade em horários do dia de menor demanda; d) potencial de operação em itinerários específicos (exemplo: ligações do tipo centro ou bairros-universidades).

No caso do usuário do carro privado, o intenso congestionamento de tráfego nos principais corredores de tráfego da cidade, tem motivado alguns motoristas, quando possível, a optar por dirigir em horários alternativos. Às vezes antecipam o horário da saída de casa com destino ao trabalho, e em outros casos retardam o horário de retorno à casa. Em ambos os casos a tentativa é de evitar trafegar em horários típicos de congestionamento. Um 
outro fator de desestímulo ao motorista é a dificuldade de estacionamento em locais de maior atração de viagens (pólos de atração como o centro da cidade). Estes grupos de motoristas apresentam um maior potencial de substituição de viagens para utilização de um serviço do tipo vans. Este fato já foi constatado em casos de empresas onde funcionários que residem em bairros próximos tem se organizado para fretar estes serviços.

Se considerarmos que cada van tem capacidade para transportar em média 10 passageiros, e ainda que a ocupação média de um carro privado na cidade está abaixo de 1,5 passageiros por veículo por viagem, existe a possibilidade de cada van vir a substituir a viagem de 6 carros privados. A redução do número de carros particulares nas ruas, por certo estaria contribuindo para a melhoria da circulação do tráfego em geral. Como conseqüências imediatas, ter-se-iam uma redução de tempos de viagem, redução de tempos de espera (para passageiros do transporte por ônibus), redução de consumo de combustível, e redução de emissões atmosféricas e sonoras. Desta forma, seria possível identificar-se pólos de geração de viagens por carro (em geral, bairros de maior poder aquisitivo) e desenvolver-se campanhas de incentivo ao uso deste serviço, com os possíveis benefícios já mencionados.

Um outro tipo de serviço adequado à operação das vans seria o de operar como um sistema alimentador de linhas troncais. Desta forma muitos usuários que se deslocam ao centro da cidade (ou a outro destino), utilizando o carro particular, poderiam ter a opção de um serviço de alta freqüência com conexões à estações de metrô, trens ou mesmo terminais de ônibus (os ônibus poderiam estar operando com prioridades - faixas exclusivas). Além de contribuir para a redução do uso do carro particular, este tipo de serviço estaria contribuindo para a otimização da operação dos serviços de transporte convencionais, através da oferta de um serviço mais uniforme (maior freqüência) ao longo do dia.

Em períodos de menor demanda do dia (entre-picos), sobretudo em ligações mais longas entre a periferia e o centro, a utilização das vans em substituição à ônibus de grande capacidade poderia não só otimizar a freqüência do serviço, mas também reduzir custos operacionais para o atual operador destes serviços. Dada a menor demanda nestes horários, a prática dos operadores de ônibus tem sido reduzir a frota operante com a conseqüente queda no nível de serviço. Esta forma de atuação tem provocando protestos 
por parte dos usuários. A utilização das vans nestes horários e rotas poderia reduzir este conflito e melhorar o atual nível de serviço.

Uma outra perspectiva de utilização dos serviços de vans seria em rotas específicas, com grande potencial de atração de usuários de carros. Um bom exemplo deste tipo de utilização seria a ligação de bairros (ou centro) com universidades. Estas universidades funcionam como polos de atração e muitas vezes se localizam em partes da cidade onde o operador do ônibus convencional não tem interesse em atender, devido à demanda irregular durante o dia. Um serviço do tipo vans poderia não só reduzir viagens de carro como também oferecer uma nova opção de deslocamento para aqueles que tentam utilizar o transporte regular. Outras ligações específicas com potencial para utilização do serviço de vans na cidade englobariam ligações do tipo Barra da Tijuca - Zona Sul (e à partir dai integração com ônibus de maior capacidade com destino ao centro); Barra da Tijuca - Vicente de Carvalho (integração com a linha 2 do Metrô); e outras.

A partir destas considerações, observa-se que regulamentar o serviço de vans como fez a secretaria municipal de transportes (somente para a operação de serviços especiais - turismo, shows, escolas, etc.), não deverá contribuir para atender a demanda existente e não atendida em rotas convencionais. É possível ainda que esta forma de regulamentação contribua para um tipo de operação clandestina, uma vez que já se identificou na cidade demanda para operação das vans.

\subsection{Problemas e Críticas ao Serviço de Vans}

Quando se critica o serviço atualmente operado pelas vans, o principal argumento apontado é a competição predatória com os ônibus e táxis, uma vez que as vans operam sem regulamentação, atraindo passageiros de outros serviços públicos oficialmente autorizados para esta atividade. Uma das possíveis causas desta competição, classificada pelo poder concedente (e pelos operadores regulamentados) de predatória, pode estar relacionada com a deficiência dos serviços prestados pelos sistemas regulamentados, como observado na seção 3 . Se os ônibus estivessem operando de forma adequada, entendendo-se por adequada, de forma a garantir tempos de viagem, tempos de espera, regularidade, conforto, confiabilidade, segurança, etc., as chances de ocorrer este tipo de competição seriam menores. As tarifas cobradas pelas vans são superiores à cobrada pelos ônibus e em 
condições normais de operação, os usuários do ônibus (geralmente de menor poder aquisitivo) tenderiam a continuar escolhendo o ônibus, em que pese a existência dos demais fatores que influenciam a escolha modal. Da mesma forma, se houvessem táxis suficientes para atender a demanda, é possível que o usuário do táxi tivesse uma menor motivação para optar pelas vans, mesmo considerando um menor custo de transporte. $O$ usuário do táxi está normalmente disposto a pagar uma tarifa superior por um serviço exclusivo e de maior conforto.

No caso específico dos táxis, o que vem ocorrendo na cidade é um interesse dos taxistas em operar seus veículos como operam as vans. O objetivo é transportar vários passageiros em uma mesma viagem (serviço conhecido popularmente como "lotadas"), cobrando a mesma tarifa para os diversos passageiros. Esta prática aumenta de forma considerável a receita por viagem do taxista. O argumento principal dos taxistas é de que estão proibidos de prestar este tipo de serviço ("lotadas") e que não seria justo liberá-lo aos operadores de vans. A van é um veículo de características tecnológicas diferentes do táxi convencional. Enquanto um táxi dispõe de apenas 4 lugares, as vans oferecem mais do que o dobro de assentos e também uma maior área total interna. Além disso, o usuário do táxi esta pagando uma tarifa diferenciada e superior aos demais sistemas exatamente para ter privacidade exclusividade em sua viagem. Não seria interessante portanto, do ponto de vista da diversificação de serviços e da regulamentação, que os taxistas operassem como as vans (dadas as diferenças tecnológicas). Conclui-se assim que na prática, as vans não concorrem de forma predatória com os táxis (nem tampouco com os ônibus). O usuário do táxi, de maior poder aquisitivo e por isso com maior flexibilidade de escolha, poderá continuar optando pelo táxi (embora passe a ter uma nova opção de transporte), por suas características de serviço exclusivo. Desta forma, a possível competição existente é a decorrente da oferta ao usuário de uma nova opção de transporte público, o que do ponto de vista da operação do sistema (aumento da oferta) é extremamente interessante e não deveria ser considerada predatória.

Um problema que deveria ser evitado nesta tentativa de regulamentação das vans é a proliferação de veículos em rotas estabelecidas pelos próprios operadores e sem coordenação com os demais sistemas. Da mesma forma, rotas já operadas por sistemas de transporte convencionais que estejam atendendo a demanda de forma adequada, também não deveriam ser ope- 
radas por sistemas do tipo vans. Como observado por Glaister (1985), este tipo de operação poderia aumentar excessivamente o volume de veículos em áreas centrais, aumentando o conflito e problemas já existentes. Não haveria ainda contribuição significativa para a melhoria da qualidade dos transportes coletivos.

Um outro aspecto que é fundamental a ser considerado na regulamentação das vans é a garantia da segurança dos usuários. Como no momento estes veículos operam de forma independente (geralmente os veículos pertencem a operadores autônomos), estão sujeitos a tratamento diferenciado no que diz respeito à manutenção do veículo. Cada operador estabelece a periodicidade e nível de manutenção de seus veículos sem obedecer nenhum padrão pré-estabelecido. Mesmo que continuem a operar de forma autônoma, será necessário garantir ao usuário segurança nestas viagens. Isto pode ser garantido através do estabelecimento de uma rotina padrão de manutenção dos veículos, que estabeleça intervalos máximos de operação entre revisões sucessivas. É importante ainda, do ponto de vista da segurança, que se garanta a habilitação adequada do condutor deste tipo de veículo.

\section{CONCLUSÕES}

Em resumo, o que é preciso ser levado em consideração no processo de regulamentação deste serviço, é que as vans são veículos que ocupam uma posição intermediária entre táxis e ônibus e devem ser regulamentadas como tal. Se estas vans operarem de forma a contribuir para a redução do número de carros privados nas ruas, elas estarão cumprindo a função esperada pelo planejador de transportes que é maximizar a capacidade dos sistemas de transporte coletivos e das vias, além de reduzir o conflito entre veículos e pedestres em áreas centrais.

O que é importante no processo de regulamentação deste serviço é não fazelo nos mesmos moldes dos atuais serviços regulamentados (ônibus e táxis) dada as características diferenciadas das vans. Além disso deve-se ressaltar que o atual sistema de regulamentação e fiscalização não tem garantido as condições mínimas de qualidade do serviço prestado. A regulamentação deve ser tal que não possibilite que as vans congestionem mais ainda o centro da cidade. Nos horários de rush deveriam ser autorizadas a operar como sistema alimentador de corredores troncais de forma que só os veículos de maior capacidade atingiriam a área central da cidade. Da mesma 
forma, em horários de menor demanda, sobretudo em ligações de bairros de menor densidade populacional e geralmente mais distantes do centro da cidade, este serviço de vans poderia ser incentivado. Veículos de grande capacidade podem operar com prejuízo nestas ligações devido a menor demanda nestes horários. As vans, além de operacionalmente se adequarem melhor a estes períodos do dia, podem garantir um serviço de maior freqüência, e portanto mais regular, o que não ocorre com os serviços de ônibus.

Um outro aspecto a ser considerado, é que regulamentar adequadamente só o sistema de vans não será suficiente para a melhoria do problema de transportes na cidade. É necessário que os demais sistemas de transporte coletivo, ônibus, metrô, trens, barcas, estejam funcionando de forma adequada para que seus passageiros cativos (ou quase cativos) não se sintam motivados a se transferir para o serviço de vans devido à má qualidade dos serviços convencionais. Torna-se imperativo uma revisão do atual sistema de concessões na operação de serviços de ônibus e táxis.

Constata-se que um número significativo de usuários das vans viajava anteriormente em outros sistemas de transporte coletivo e passaram a optar pelas vans pela garantia de um serviço de qualidade. Estes usuários se submetem a comprometer uma maior parcela de seus salários, utilizando o serviço das vans (e até mesmo o serviço de ônibus denominados "piratas" - sem registro), simplesmente pela garantia da prestação do serviço. Fica claro a total inadequação do transporte regular que opera na cidade para garantir um nível mínimo de serviço. Caso o transporte regular fosse oferecido de forma adequada, a probabilidade deste usuário em optar pelos serviços de vans seria possivelmente menor, dado o maior custo incorrido (embora outros fatores possam induzi-lo a esta escolha).

Mais ainda, se as vans estão no momento ocupando um lugar no mercado mais amplo do que se esperaria, isto se dá devido a total incapacidade do sistema regulamentado em atender a demanda de forma eficaz. Em áreas da cidade como a da baixada de Jacarepaguá o próprio poder concedente admite que existe atualmente uma demanda por serviços maior que a oferta (Seminário "Alternativas para o Trânsito na Cidade do Rio de Janeiro" Clube de Engenharia - Julho 1996). 
Um papel importante, que a regulamentação das vans deve incentivar é o de diminuir o número de carros particulares em vias mais congestionadas da cidade. Para isto é preciso que operem de forma integrada e coordenada aos demais sistemas regulamentados. Precisam também manter uma qualidade de serviço diferenciada da oferecida pelos ônibus, de forma a aumentar as chances de sucesso na atração do usuário do carro particular.

Penalizar ou mesmo proibir a operação deste novo serviço de transporte coletivo sem antes buscar a melhoria dos serviços de transporte regular é no mínimo insensato. É importante diversificar as alternativas de transporte público, oferecendo opções variadas e de qualidade ao usuário. As vans viriam ampliar a oferta de transporte público na cidade, com seu potencial para operar de forma complementar e subsidiária a todos esses sistemas.

\section{REFERÊNCIAS BIBLIOGRÁFICAS}

BALASSIANO, R. (1995) The Future of the Urban Bus. PhD Thesis, University of Westminster, London.

BANISTER, D. (1992) The British Experience of Bus Deregulation in Urban Transport: Lessons for Europe. Working Paper 5, Planning and Development Research Centre, UCL, London.

BANISTER, D., MACKETT, R.L. (1990) The Minibus: Theory and Experience, and their Implications. Transport Reviews, Vol. 10, No 3, pp. 189-214.

COUTO, J.L., PEREIRA, W.A.A. (1992) Transporte Clandestino e a Desregulamentação. Revista dos Transportes Públicos, Ano 14, 4o Trim., pp. 131-140.

DOURADO, A.B.F. (1995) Transporte "Informal x Formal": Verdadeira ou Falsa Questão? Revista dos Transportes Públicos, Ano 17,1o Trim., pp. 81-91.

GEIPOT (1987) Anuário Estatístico dos Transportes. Brasília.

GLAISTER, S. (1985) Competition on an Urban Bus Route. Journal of Transport Economics and Policy, January, pp. 65-81.

GLAISTER, S. (1986) Bus Deregulation, Competition and Vehicle Size. Journal of Transport Economics and Policy, May, pp. 217-244.

GUEDES, et al (1996) Demanda e Elasticidades nos Transportes: O Caso 
do Transporte Público na Região Metropolitana do Rio de Janeiro. Monografia, Programa de Engenharia de Transportes, PET/COPPE/ UFRJ, Rio de Janeiro.

TANABORIBOON, Y, AGAD, V.B. (1990) Bangkok's Indispensible Mode of Public Transport. In Land Transport and Development - International Conference, Dunkirk, 18-22 June, pp. 341-346.

TANABORIBOON, Y., MADRONA, L.G. (1990) Silor Leks: A Novel Solution to the Mobility Problems in the Developing Countries - A Case Study in Bangkok. In Land Transport and Development - International Conference, Dunkirk, 18-22 June, pp. 347-352.

UMRIGAR, F., et al (1991) Measuring the Effectiveness of Urban Bus Systems in India Under Existing Organizational Set Ups. In PTRC - Urban Transport in Developing Countries - Lessons in Innovation, London, pp. 160-169.

WHITE, P. (1991) Three Years' Experience of Bus Service Deregulation in Britain. Paper for Plenary Session and Workshop 6, at the Second International Conference on Privatization and Deregulation in Passenger Transportation, Tampere.

WHITE, P. (1995) Deregulation of Local Bus Services in Great britain: An Introductory Review. Transport Reviews, Vol. 15, No 2, pp. 185-209.

WHITE, P., CASSIDY, S. (1993). The Contribution of Marketing to Economic Performance of Mini and Midi Bus Operations Since 1986. Paper for Sixth Annual Minibus Conference, Swansea Institute, Swansea.

WHITE, P., et al (1992) Cost Benefit Analysis of Urban Minibus Operations. Transportation 19, pp. 59-74. 